\title{
PRIMARY CLOSURE FOLLOWING COMMON BILE DUCT EXPLORATION FOR CHOLEDOCHOLITHIASES
}

\author{
Rosemary Vumkhoching ${ }^{1}$, Chabungbam Gyan Singh², Khumallambam Ibomcha Singh ${ }^{3}$, N. Jitendra ${ }^{4}$, Ng. Javan $^{5}$ \\ ${ }^{1}$ Assistant Professor, Department of Surgery, Jawaharlal Nehru Institute of Medical Sciences, Imphal, Manipur. \\ ${ }^{2}$ Assistant Professor, Department of Surgery, RIMS, Imphal, Manipur. \\ ${ }^{3}$ Senior Resident, Department of Surgery, Jawaharlal Nehru Institute of Medical Sciences, Imphal, Manipur. \\ ${ }^{4}$ Professor, Department of Surgery, Jawaharlal Nehru Institute of Medical Sciences, Imphal, Manipur. \\ ${ }^{5}$ Associate Professor, Department of Surgery, Jawaharlal Nehru Institute of Medical Sciences, Imphal, Manipur.
}

\section{ABSTRACT}

\section{OBJECTIVE}

To assess the outcome of primary closure of common bile duct following exploration for choledocholithiases.

\section{STUDY DESIGN}

Descriptive case series.

Place and time of study: Department of General surgery unit III, Jawaharlal Nehru Institute of Medical Sciences, Imphal from Feb. 2010 to August 2015.

\section{MATERIAL AND METHODS}

Clinical record of all patients of choledocholithiases undergoing primary closure was retrieved. Patient's demography, intrao perative finding, operating time, hospital stay and operative complications were noted. SPSS version 11 used for analysis of data.

\section{RESULTS}

A total of 52 patients were studied, having male:female ratio of 1:6.4. Mean operating time was 100.3 minutes. The overall complication rate was $5.76 \%$. Average hospital stay was 7.40 days. None of the patients developed post-operative peritonitis. There was no mortality in our study.

\section{CONCLUSION}

Primary closure following CBD exploration is a safe and effective measure for CBD stone associated with low complication rate and faster recovery.

KEYWORDS: Common Bile Duct, Choledochotomy, Choledocholithiases.

HOW TO CITE THIS ARTICLE: Rosemary Vumkhoching, Chabungbam Gyan Singh, Khumallambam Ibomcha Singh, N. Jitendra, Ng. Javan. "Primary Closure Following Common Bile Duct Exploration for Choledocholithiases." Journal of Evolution of Medical and Dental Sciences 2015; Vol. 4, Issue 95, November 26; Page: 16069-16071, DOI: 10.14260/jemds/2015/2347.

\section{INTRODUCTION}

JNIMS is a recently established Medical College in Manipur, eastern most state of India bordering Myanmar. This study was conducted in surgery unit III, JNIMS. Choledocholithiases is a common biliary condition requiring invasive intervention. It is managed endoscopically, laparoscopically, traditional surgery, interventional radiology, extracorporeal shock wave lithotripsy or a combination of methods. Traditionally, Common Bile Duct (CBD) is closed over T-tube, but potential of complications exists with this therapeutic modality. This includes bacteraemia, dislodgement of tube, obstruction and/or fracture of tube, leakage of bile after T-tube removal. All of these lead to prolonged length of hospital stay.1,5

Financial or Other, Competing Interest: None.

Submission 03-11-2015, Peer Review 04-11-2015,

Acceptance 16-11-2015, Published 25-11-2015.

Corresponding Author:

Dr. Rosemary Vumkhoching,

Assistant Professor,

Department of Surgery,

JNIMS, Imphal-795005, Manipur.

E-mail: rosemanna69@gmail.com

DOI:10.14260/jemds/2015/2347.
Primary closure of the CBD was first described by Halstead in 1917. But surgeons all over the world preferred $\mathrm{T}$ tube closure. Currently, primary closure of CBD has been described in literature to overcome these adverse consequences of T-tube.6,7 This study was designed to assess the outcome of primary repair of CBD in terms of operating time, duration of hospital stay and postoperative complications and feasibility of this recent technique in the setting of a recently established Medical College.

\section{METHODOLOGY}

This retrospective and prospective case series was conducted at the Department of Surgery, unit III of JNIMS, Imphal. Clinical records of all the patients who underwent open CBD exploration with primary closure between Feb 2010 to August 2015 were retrieved. USG Abdomen was repeated in our institute as a unit protocol for those patients who were evaluated outside JNIMS. In doubtful cases MRCP was done. All patients were operated through right subcostal incision. After cholecystectomy except in one case, supraduodenal choledochotomy was done and CBD explored. One patient underwent CBD exploration via cystic duct. 
Stones were retrieved with Desjardin forceps and CBD irrigated with normal saline. Proximal and distal patency were checked in all cases. Rigid nephroscope was used to visualize clearance of stone in few cases. Flexible choledochoscope was used to check for complete clearance and patency of both proximal and distal bile duct from February 2015. Choledochotomy was closed primarily using 3-0 vicryl in all cases. A subhepatic drain was kept in all cases, which was removed when there was less than $50 \mathrm{ml}$ serous fluid. All patients were routinely given IV third generation cephalosporin for 3 days and converted to oral antibiotic as required. Patient's demographics (Like age and gender), operative time, duration of hospital stay, and postoperative complications including bile leakage, biliary peritonitis, and postoperative jaundice were recorded on a proforma. The data was compiled and the results tabulated using SPSS (Version 11, 2002, SPSS Inc., Chicago, IL, USA).

\section{EXCLUSION CRITERIA}

Those patients with hepatolithiasis, CBD diameter less than $12 \mathrm{~mm}$, who had h/o acute pancreatitis and suppurative cholangitis in the past were excluded from the study.

\section{RESULTS}

A record of 52 patients was retrieved who underwent open choledochotomy for ductal stone followed by primary closure. Fifty one patients had secondary stones and one patient had primary CBD stone presenting 25yrs. after cholecystectomy. There were $07(13.46 \%)$ males and $45(86.53 \%)$ females. The male-to-female ratio was $1: 6.4$, the ages of the patients ranged from 23-80 years with mean 45.53 years. Majority of patients have single stone, 12 patients have 2 stones and 3 patients have 3 or more stones. Operating time ranged from 86 minutes to 116 minutes. Before procuring choledochoscope for the institute, nephroscope was used to see for stone clearance. Subsequently, when choledochoscope become available in February 2015, it has been used routinely for all the cases operated. Average operating time was 100.93 minutes. Drain was removed most commonly between POD 5 and 7 .

One patient had drain removed on POD10; she had prolonged ileus and another two on POD12 and POD13, both of whom had transient bile leak. Hospital stay range from 7 days to 16 days. Average hospital stay was 7.40 days. Overall complication rate was $5.76 \%$. Transient bile leak was observed in two patients and one patient had prolonged ileus. None of our patients developed post-operative peritonitis. No patients required operative intervention for any of the complications. There was no mortality in our study.

\section{DISCUSSION}

JNIMS is a recently established Medical College in Manipur situated in the eastern border of India. There is no facility for ERCP and laparoscopic CBD exploration in JNIMS. Choledocholithiases have been managed traditionally with Ttube closure or more recently with minimally invasive procedure like laparoscopic CBD exploration or with help of ERCP. T-tube drainage of the common bile duct is performed for the following reasons (Williams 1994) (a) Post-operative decompression of the common bile duct (If outflow obstruction occurs) (b) Post-operative visualization of common bile duct (c) Availability of a T-tube to extract common bile duct stones with a Burhenne steerable catheter (Burhenne 1973).8,9 However, the use of T-tube is not without complications. It is associated with peritubal leakage, excess bile drainage, electrolyte imbalance, peritubal cellulitis, sepsis, necrotizing fasciitis, post T-tube removal bile leakage etc. ${ }^{10,11}$

This study showed no major morbidity associated with primary repair of bile duct after supraduodenal choledochotomy for choledocholithiases. Moreover, this technique carried shorter operating time and duration of hospital stay. Zhang et al. noticed $28.6 \%$ of complications rate associated with T-tube in contrast to $11.1 \%$ in whom primary repair was performed.12 Biliary complications are considered to be the major consequence after primary repair of CBD; however, their overall frequencies are much less than that of T-tube closure. Ahmad and Colleagues observed 22\% and $8.9 \%$ of these complications in T-tube and primary closure groups respectively. ${ }^{13}$ Ambreen et al. noticed one (6.3\%) patient of bile leakage that subsided conservatively, which is comparable to this study. None of the patients in this study experienced postoperative jaundice and biliary peritonitis. This is comparable to the study conducted by Ambreen and associates. ${ }^{14}$ However, Perez et al. reported biliary peritonitis after removal of T-tube. ${ }^{15}$

As a result of postoperative complications and long placement of T-tube till removal, duration of hospital stay gets prolonged. This forced surgeons to move towards primary repair technique that have been advised in literature. In this study, mean duration of hospital stay was 7.40 days, which is nearly comparable to the study conducted by Decker et al. The hospital stay was significantly longer in the T-tube group in three trials (Payne 1986; Williams 1994; Marwah 2004).16

The mean operating time in our study was 100.93 minutes, comparable to the study by Ha and Colleagues (95 minutes). ${ }^{17}$ Williams et al. (Williams 1994) found no significant difference in the operating time between the two groups (median operating time in both groups $=120 \mathrm{mins}$ ). Marwah et al. (Marwah 2004) reported a significantly lower operating time in the primary closure group compared to the T-tube group (Mean 87.8 versus 116.7 minutes, $\mathrm{P}<0.001$ ). ${ }^{18}$

This study is distinctive in approach, but has a limitation of being a descriptive analysis. This study shows the possibility of primary bile duct closure without putting $\mathrm{T}$ tube and is another good alternative where laparoscopic CBD exploration and/or ERCP is not available as has been shown by some other authors too. To correlate the complications and further comparison between the two treatment options, randomized clinical trials will be needed to strengthen the scientific evidence in favour of primary closure.

\section{CONCLUSION}

Primary closure of CBD is a safe and effective measure associated with low complication rates. It can be done in most of the cases of choledocholithiases even in the setting of a very limited resource.

\section{REFERENCES}

1. Moreaux J. Tradtional surgical management of common bile duct stones: a prospective study during a 20-years' experience. Am J Surg 1995;169:220-6. 
2. Neoptolemos JP, Davison BR, Lloyd D, Shaw DE, Carr-Lock DL, Fossard DP. Study of common bile duct exploration and endoscopic sphincterotomy in a consecutive series of 438 patients. Br J Surg 1987;74:916-21.

3. Ihse I, Borch K, Carlsson P, Lindstrom E, Tiseliys HG. Extracorporeal shock wave lithotripsy of bile duct stones. Acta Chir Scand 1990;156:87-90.

4. Hotta T, Taniguchi K, Kobayashi Y, Johata K, Sahara M, Naka $\mathrm{H}$, et al. Biliary drainage tube evaluation after common bile duct exploration for choledocholithiasis. HepatoGastroenterology 2003;50:315-21.

5. Ahmed I, Pradhan C, Beckingham IJ, Brooks AJ, Rowlands BJ, Lobo DN. Is a T-tube necessary after common bile duct exploration? World J Surg 2008;32:1485-8.

6. Ha JP, Tang CN, Siu WT, Chau CH, Li MK. Primary closure versus T-tube drainage after laparoscopic choledochotomy for common bile duct stones. Hepatogastroenterology 2004;51:1605-8.

7. Alhamdani A, Mahmud S, Jameel M, Baker A. Primary closure of choledochotomy after emergency laparoscopic common bile duct exploration. Surg Endosc 2008;22:21905.

8. Williams JA, Treacy PJ, Sidey P, Worthley CS, Townsend NC, Russell EA. Primary duct closure versus T-tube drainage following exploration of the common bile duct. The Australian and New Zealand Journal of Surgery 1994;64(12):823-6.

9. Burhenne HJ. Nonoperative retained biliary tract stone extraction. A new roentgenologic technique. American Journal of Roentgenology 1973;117(2):388-99.
10. Gillatt DA, May RE, Kenedy R, Longstaff AJ. Complications of T-tube drainage of common bile duct. Ann R Coll Surg Engl 1985;67:370-1.

11. Neoptolemos JP. Complications of T-tube draiage the common bile duct. Ann R Coll Surg Engl 1986;68:326.

12. Zhang WJ, Xu GF, Wu GZ, Li JM, Dong ZT, Mo XD. Laparoscopic exploration of common Bile duct with primary closure versus T-tube drainage: a randomized clinical trial. J Surg Res 2009;157:e1-5.

13. Ahmad I, Jan AU, Ahmad R. Obstructive Jaundice. J Postgrad Med Inst 2001;15:194-8.

14. Ambreen M, Shaikh AR, Jamal A, Qureishi JN, Dalwani AG, Memon MM. Primary closure versus T-tube drainage after open choledochotomy. Asian J Surg 2009;32:21-5.

15. Perez G, Escalona A, Jarufe N, Ibanez L, Viviani P, Garcia C et al. Prospective randomized study of T-tube versus biliary stent for common bile duct decompression after open choledochotomy. World J Surg 2005;29:869-72.

16. Primary closure versus T-tube drainage after open common bile duct exploration (Review) Copyright (c) 2009 the Cochrane Collaboration. Published by JohnWiley \& Sons, Ltd.

17. Ha JP, Tang CN, Siu WT, Chau CH, Li MK. Primary closure versus T-tube drainage after laparoscopic choledochotomy for common bile duct stones. Hepatogastroenterology 2004;51:1605-8.

18. Marwah S, Singh I, Godara R, Sen J, Marwah N, Karwasra RK. Evaluation of primary duct closure vs T-tube drainage following choledochotomy. Indian Journal of Gastroenterology 2004;23(6):227-8.

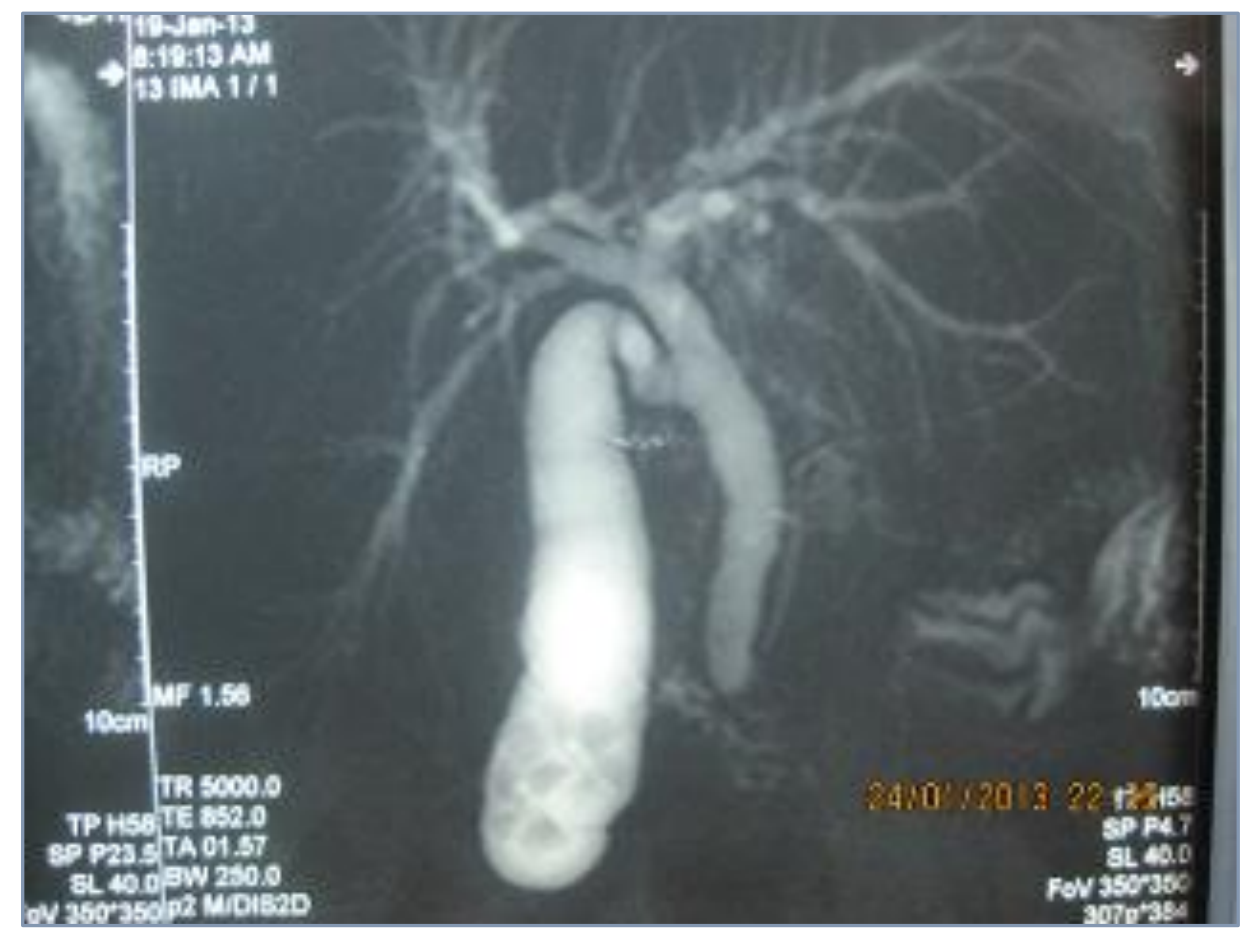

Fig. 1: MRCP showing CBD Stone 